University of South Carolina

Scholar Commons

$1-2010$

\title{
Resting Energy Expenditure Changes With Weight Loss: Racial Differences
}

\author{
Xuewen Wang \\ University of South Carolina - Columbia, xwang@mailbox.sc.edu \\ Tongjian You \\ Leon Lenchik \\ Barbara J. Nicklas
}

Follow this and additional works at: https://scholarcommons.sc.edu/

sph_physical_activity_public_health_facpub

Part of the Public Health Commons

\section{Publication Info \\ Postprint version. Published in Obesity, Volume 18, Issue 1, 2010, pages 86-91. Racial differences. Obesity, 18(1), 86-91. \\ DOI: $10.1038 /$ oby. 2009.163 \\ (c) Obesity, 2010, Nature Publishing Group \\ http://www.nature.com/oby/journal/v18/n1/full/oby2009163a.html}

Wang, X., You, T., Lenchik, L., \& Nicklas, B. J. (2010). Resting energy expenditure changes with weight loss:

This Article is brought to you by the Physical Activity and Public Health at Scholar Commons. It has been accepted for inclusion in Faculty Publications by an authorized administrator of Scholar Commons. For more information, please contact digres@mailbox.sc.edu. 


\title{
Resting energy expenditure changes with weight loss: racial differences
}

\author{
Xuewen Wang ${ }^{1}$, Tongjian You ${ }^{2}$, Leon Lenchik ${ }^{3}$, and Barbara J. Nicklas ${ }^{1}$ \\ ${ }^{1}$ Section on Gerontology and Geriatric Medicine, Wake Forest University School of Medicine, \\ Winston-Salem, NC \\ ${ }^{2}$ Department of Exercise and Nutrition Sciences, University at Buffalo, State University of New York, \\ Buffalo, NY \\ ${ }^{3}$ Department of Radiology, Wake Forest University School of Medicine, Winston-Salem, NC
}

\begin{abstract}
It is controversial whether weight loss reduces resting energy expenditure (REE) to a different magnitude in black and white women. This study was to determine whether changes in REE with weight loss were different between black and white postmenopausal women, and whether changes in body composition (including regional lean and fat mass) were associated with REE changes within each race. Black $(n=26)$ and white $(n=65)$ women $\left(\right.$ age $=58.2 \pm 5.4$ years, $25<$ BMI $\left.<40 \mathrm{~kg} \cdot \mathrm{m}^{-2}\right)$ completed a 20-week weight loss intervention. Body weight, lean and fat mass (total body, limb and trunk) via dual energy X-ray absorptiometry, and REE via indirect calorimetry were measured before and after the intervention. We found that baseline REE positively correlated with body weight, lean and fat mass (total, limb, and trunk) in white women only ( $\mathrm{p}<0.05$ for all). The intervention decreased absolute REE in both races similarly $\left(1279 \pm 162\right.$ to $1204 \pm 169 \mathrm{kcal}^{-\mathrm{day}}{ }^{-1}$ in blacks; $1315 \pm 200$ to

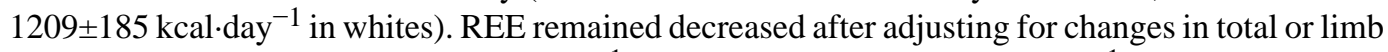

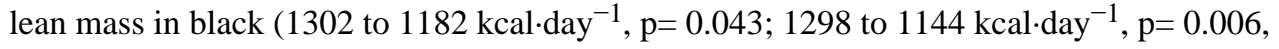
respectively), but not in white, women. Changes in REE correlated with changes in body weight (partial $r=0.277$ ) and fat mass (partial $r=0.295,0.275$, and 0.254 for total, limb, and trunk, respectively; $\mathrm{p}<0.05$ ) independent of baseline REE in white women. Therefore, with weight loss, REE decreased in proportion to the amount of fat and lean mass lost in white, but not black, women.
\end{abstract}

\section{Keywords}

energy expenditure; weight loss; body composition; race

\section{INTRODUCTION}

Non-Hispanic black women are more likely to be obese compared with non-Hispanic white women (1). Since obesity is the result of an extended period of energy surplus, one potential factor responsible for the higher prevalence of obesity in blacks could be lower energy expenditure. Resting energy expenditure (REE) represents the largest fraction (50-70\%) of an individual's total daily energy expenditure (2), and in some cases, a low REE predicts weight gain $(3 ; 4)$. The majority of data support a lower REE in black than white women after adjusting for body size and the total amount of lean and fat mass(5-13).

Correspondence: Xuewen Wang, PhD, Division of Geriatrics and Nutritional Sciences, Washing University School of Medicine, 660 S. Euclid Ave; Campus Box 8031, St. Louis, MO 63110, Tel (o): 314-362-8203, xwang@ dom.wustl.edu . 
Loss of body weight with energy restriction consistently results in a lower REE (14-19); however, whether reductions in REE with weight loss are similar in blacks and whites is controversial. One study showed that weight loss decreased REE to a greater extent in black than white women, after adjustment for initial REE and changes in lean mass and fat mass (15). In contrast, two other studies found that REE of black women remained proportionately lower than that of white women $(16 ; 17)$. Another study in postmenopausal women showed that after a small amount of weight loss $(2-3 \mathrm{~kg})$ induced by aerobic exercise training, REE decreased in black women, but was unchanged in white women (20). It is important to elucidate this in that REE can potentially affect body weight and black women tend to lose less weight than white women given the same weight loss treatments $\left(15 ;{ }^{21}-24\right)$.

It is suggested that lean mass distribution may contribute to the racial difference in REE. Hunter et al. reported a 7.5\% lower REE in black than white women after adjusting for lean mass; however, this difference disappeared after adjusting for trunk lean mass (25). Gallagher et al. using MRI quantified the mass of selected high metabolic rate organs (including liver, kidneys, spleen, heart and brain), and determined that half of the observed difference in REE between black and white men and women after adjustment for age, fat, and fat-free mass, was explained by differences in the mass of these high metabolic rate organs (26). However, there is no information regarding whether any different changes in regional lean mass (trunk and limb) contribute to any potential racial difference in REE changes with weight loss.

Moreover, the changes in REE with weight loss may be associated with different factors for women of different races. For example, in white women, changes in REE were related to their initial weight; while in blacks, they were not related (15). Therefore, the purpose of this study was to determine whether there were differences between black and white postmenopausal women in the magnitude of changes in REE in response to weight loss. We also examined whether initial body composition and changes in body composition (including regional lean and fat mass) were associated with weight loss-induced REE changes within each race.

\section{RESEARCH METHODS AND PROCEDURES}

\section{Participants}

Participants in this study were postmenopausal women who volunteered to participate in a randomized clinical trial designed to determine whether the intensity of aerobic exercise affects the loss of abdominal adipose tissue under conditions of equal energy deficit (ClinicalTrials.gov identifier: NCT00664729). All women were recruited from the Piedmont Triad area of North Carolina and were enrolled in the study based on the following inclusion/ exclusion criteria: 1 ) postmenopausal (age $=50-70$ years, and at least one year without menses), 2) overweight or obese (BMI $=25-40 \mathrm{~kg} \cdot \mathrm{m}^{-2}$ and waist girth $>88 \mathrm{~cm}$ ), 3) nonsmoking, 4) not on hormone therapy, 5) sedentary ( $<15$ min of exercise, 2 times/wk) in the past 6 months, and 6$)$ weight-stable $(<5 \%$ weight change) for at least 6 months prior to enrollment. The study was approved by the Wake Forest University School of Medicine Institutional Review Board and all women signed an informed consent form to participate in the study according to the guidelines for human research.

Initial screening included a medical history review, physical examination, fasting blood profile, and 12-lead resting electrocardiogram. Participants with evidence of untreated hypertension (blood pressure >160/90 $\mathrm{mmHg}$ ), hypertriglyceridemia (triglycerides $>400 \mathrm{mg} / \mathrm{dl}$ ), insulindependent diabetes, active cancer, liver, renal or hematological disease, hyper- or hypothyroidism, or other medical disorders were excluded. On a second screening visit, the participants underwent a graded exercise test to exclude those with an abnormal cardiovascular response to exercise. The maximal heart rate achieved during the graded exercise test was used in the determination of the appropriate exercise intensity. 
A total of 112 eligible ( 28 black and 84 white) women were randomly assigned to participate in either a hypocaloric diet only $(n=34)$, a diet plus low-intensity exercise $(n=40)$, or a diet plus high-intensity exercise $(n=38)$ intervention for a period of 20 weeks. Race was ascertained based on self-report. We report here data from women who completed the intervention and had REE and body composition measured at both baseline and post-intervention. The reasons for not completing the study include family or life situation $(n=11)$, adverse event not related to the study intervention $(n=2)$, diet incompatibility $(n=3)$, and not responding to contact $(n=1)$. One woman missed the post-intervention REE measurement and three women did not have a satisfactory REE test at baseline or after intervention (see criteria in Methods). The final sample included 26 black and 65 white women (27,35, and 29 in the diet only, diet plus low-intensity exercise, and diet plus high-intensity exercise groups, respectively).

\section{Study intervention}

Upon entry into the study, all women completed a 4-day food record which was used as an initial measure of dietary intake. Individual energy needs were calculated from REE directly measured via indirect calorimetry, and applying an activity factor based on each woman's description of her daily activities (1.2-1.3 for sedentary lifestyle). The calorie deficits of all women were adjusted to $\sim 2800 \mathrm{kcal} \cdot \mathrm{week}^{-1}\left(\sim 400 \mathrm{kcal} \cdot \mathrm{day}^{-1}\right)$. The deficits for the diet only group resulted totally from reduction in dietary intake, whereas deficits for the diet plus exercise groups resulted from both dietary intake restriction $\left(\sim 2400 \mathrm{kcal} \cdot \mathrm{week}^{-1}\right)$ and exercise energy expenditure.

All women were given food for their lunch and dinner, which was prepared and provided by the Wake Forest University General Clinical Research Center metabolic kitchen. These meals were prepared individually after women chose from a hypocaloric menu designed by the registered dietitian to provide a balanced, healthy diet. Calorie make-up of the diet was approximately $25 \%$ from fat, $15 \%$ from protein, and $60 \%$ from carbohydrate. Women purchased and prepared their breakfast meal from the same menu in consultation with the dietitian. They were allowed two free days per month, where they were given guidelines for diet intake and asked to report their intake on those days. They were also provided with a daily calcium supplement (1000 mg/day). Non-caloric, non-caffeinated beverages were allowed ad libitum. All women were asked to keep a log of everything they ate or drank. The records were monitored weekly by the dietitian to verify compliance to the diet. The average daily calorie intake recorded by participants was $100.2 \pm 1.5 \%$ (mean \pm SD) of the provided calorie level.

The exercise prescription involved center-based treadmill walking three times/week at a target heart rate calculated from the Karvonen equation [(HRR $\times$ (intensity) $)+$ resting heart rate] (27), where heart rate reserve (HRR) is maximal heart rate, obtained from each subject's graded exercise test, minus resting heart rate. The duration and intensity of the exercise prescription progressed from 15-20 min at 45-50\% of HRR during the first week to $55 \mathrm{~min}$ at $45-50 \%$ HRR for the low-intensity exercise group and $30 \mathrm{~min}$ at 70-75\% HRR for the high-intensity exercise group. Participants attended $91.3 \pm 8.3 \%$ of the exercise sessions.

\section{Measurements}

Body composition-Before and after the 20-week intervention, height and weight were measured with shoes and jackets or outer garments removed; lean body mass, fat mass, percent body fat, as well as limb and trunk lean and fat mass were measured by dual energy X-ray absorptiometry (DXA) (Hologic Delphi QDR, Bedford, MA). Regions of interest were predefined as a template overlay provided by the manufacturer's software and could be adjusted to match the participant's anatomy. Trunk was separated from arms, legs, and head. Limb mass included mass of both arms and legs. The coefficient of variance for body composition 
assessment (lean, fat mass and bone mineral content) using this method is between 1-3\%(28; 29).

Resting energy expenditure-REE was measured before and after the 20-week intervention using indirect calorimetry following 12 or more hours of fasting. For the postintervention measurement, there was no effort to stabilize body weight prior to the test. Participants were instructed not to participate in heavy physical activity 24 hours prior to the measurement. They were allowed to breathe freely through a face mask, while expired air was collected through a one-way valve and analyzed using a MedGraphics CCM/D metabolic cart (MedGraphics Inc., Minneapolis, MN). REE was calculated from each determination of $\mathrm{VO}_{2}$ and $\mathrm{VCO}_{2}$ using Weir's equation (30). Participants rested quietly for 15-30 minutes before the collection of data and for an additional 30 minutes during which data were collected. During the measurement, steady state was defined as $\pm 5 \%$ in oxygen consumed. For those in the exercise groups, REE was measured at least 48 hours after the previous exercise session.

\section{Statistics}

Statistical analyses were performed using SAS software, version 9.1 (SAS Institute, Cary, NC). Descriptive statistics were calculated. Analysis of variance was used to compare baseline and the changes from baseline to post-intervention between races. In comparisons of REE between races, body composition measures were used as covariates. Analysis of variance with repeated measures including race and race $\times$ time interaction was used to compare means at postintervention to means at baseline. Treatment group $\times$ race or treatment group $\times$ time interactions for body composition measure and REE were examined within black and white women. Multiple regression was used to determine correlates of REE changes. An alpha level of 0.05 was selected to denote statistical significance.

\section{RESULTS}

Women in the study were an average of 58.2 \pm 5.4 years old and $13.1 \pm 10.1$ years postmenopausal. At baseline, there were no differences in age $(\mathrm{p}=0.527)$, body weight $(\mathrm{p}=$ 0.820 ), body composition ( $\mathrm{p}=0.878,0.755,0.334,0.173,0.736,0.328,0.818,0.459,0.692$, for BMI, total fat and lean mass, percent body fat, limb fat and lean mass, trunk fat and lean mass, trunk to limb lean mass ratio, respectively), or REE ( $\mathrm{p}=0.521)$ among the treatment groups. The proportion of black women in the diet only, diet plus low-intensity exercise, and diet plus high-intensity exercise groups was not different (Chi-square $\mathrm{p}=0.233$ ).

\section{Body composition at baseline and changes with intervention (Table 1)}

Table 1 includes body weight and composition measures at baseline and post-intervention and their changes by race. Since there were no treatment group differences in body weight or composition at baseline or changes with intervention, we do not present data by treatment group. At baseline, black women were heavier and had a higher BMI $(\mathrm{p}<0.05)$. They had significantly more total lean and fat mass and more limb lean and fat mass than white women $(\mathrm{p}<0.05)$. A lower trunk to limb lean mass ratio in black than white women was also found. Total \% body fat, and trunk lean and fat mass were not different between the two races. However, after adjustment for body weight, black women had more limb lean mass (adjusted mean: 23.4 vs. $22.4 \mathrm{~kg}, \mathrm{p}=0.006)$ and less trunk lean mass $(24.8 \mathrm{vs} .26 .0 \mathrm{~kg}, \mathrm{p}=0.002)$ than white women.

The weight loss intervention significantly decreased body weight, BMI, \% body fat, lean and fat mass (total, limb, and trunk) in both races (Table 1; $<<0.0001$ ). However, the magnitude of decrease in body weight, BMI, \% fat, fat mass (total and trunk) was greater in white than black women $(\mathrm{p} \leq 0.05)$. After adjusting for initial body weight, the decreases in the above 
measures $(\mathrm{p}<0.01$ for all) as well as limb fat mass $(\mathrm{p}<0.01)$ and trunk lean mass $(\mathrm{p}=0.046)$ were greater in white women. The trunk to lean mass ratio, however, did not change in white ( $p>0.05)$, but showed a trend to increase in black women $(p=0.071)$.

\section{Resting energy expenditure (Figure 1 and Figure 2}

As with the body composition measures, REE at baseline and changes in REE with weight loss were not different by treatment group. At baseline, black and white women had a similar absolute REE. However, after adjusting REE for total or limb lean mass, or total lean mass and trunk to limb lean mass ratio, black women showed a 7-9\% lower REE than white women ( $\mathrm{p}=$ $0.017,0.003$, and 0.035 , respectively; Figure 1). REE adjusted for body weight, fat mass (total, limb, or trunk), or trunk lean mass was not different between races ( $p>0.05$ for all). Additionally, adjusting for limb lean mass together with body weight, REE of black women was lower than white women (adjusted mean: 1219 vs. $1340 \mathrm{kcal} \cdot \mathrm{day}^{-1}, \mathrm{p}=0.004$ ), while adjusting for total lean mass together with body weight, REE was not different between the

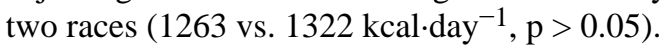

The weight loss intervention significantly decreased absolute REE in both races $(1279 \pm 162$ to $1204 \pm 169 \mathrm{kcal} \cdot \mathrm{day}^{-1}$ in blacks, $\mathrm{p}=0.022 ; 1315 \pm 200$ to $1209 \pm 185 \mathrm{kcal} \cdot \mathrm{day}^{-1}$ in whites; $\mathrm{p}<$ 0.001; REE decreased in 71 of the 91 women, and changes in REE ranged from -403 to 386 $\mathrm{kcal} \cdot \mathrm{day}^{-1}$ ) but the magnitude of this decrease was not different between black and white women. In black women, REE remained decreased after adjusting for changes in total or limb lean mass, or changes in total lean mass and trunk to limb lean mass ratio $(\mathrm{p}=0.043,0.006$, 0.025 , respectively; Figure 2a), but remained unchanged after adjusting for changes in body weight and fat mass (total, limb, or trunk). There was no weight loss-induced change in REE in white women after adjusting for changes in weight, lean or fat mass (total, limb, or trunk), or total lean mass and trunk to limb lean mass ratio (Figure $2 b$ ).

\section{Correlates of resting energy expenditure and its change after weight loss}

At baseline, REE correlated with body weight ( $\mathrm{r}=0.58, \mathrm{p}<0.001)$, lean mass (total, limb, and trunk) ( $\mathrm{r}=0.68,0.66$, and 0.65 , respectively; $\mathrm{p}<0.001)$ and fat mass (total, limb, and trunk) $(\mathrm{r}=0.35, \mathrm{p}=0.004 ; \mathrm{r}=0.26, \mathrm{p}=0.041 ; \mathrm{r}=0.36, \mathrm{p}=0.003)$ in white women. Thus, white women who were heavier and had more lean and fat mass had higher REE. However, in black women, there were no significant correlations between REE and any of the body composition measures at baseline $(\mathrm{r}=0.23,0.13,0.12,0.14,0.24,0.17,0.25$, respectively; $\mathrm{p}>0.05)$.

Changes in REE with weight loss were inversely related to baseline REE in both races ( $\mathrm{r}=$ $-0.440, p=0.025$ for blacks; $r=-0.473, p<0.001$ for whites). We also determined whether changes in body composition as a result of the interventions were associated with changes in REE. In white women, independent of baseline REE, changes in REE correlated with changes in body weight (partial $r=0.277, p<0.05$ ) and fat mass (partial $r=0.295,0.275$, and 0.254 for total, limb, and trunk fat mass, respectively; $\mathrm{p}<0.05$ ), but not lean mass (partial $\mathrm{r}=0.19$ and 0.14 , for total and limb lean mass, respectively; $p>0.05$ ). Thus, the more body weight or fat mass lost, the greater REE decreased in white women. In addition, changes in REE correlated with changes in trunk lean mass independent of baseline REE in white women in the diet plus high-intensity exercise group (partial $\mathrm{r}=0.43, \mathrm{p}=0.039$ ). In contrast, in black women, a trend for a significant inverse relationship was found for changes in REE and limb lean mass (partial $\mathrm{r}=-0.359, \mathrm{p}=0.078$ ). A trend for a significant treatment group interaction was also found for changes in REE and lean body mass $(\mathrm{p}=0.058)$ with an inverse relationship in black women in the diet only group $(r=-0.81, p=0.009)$, independent of baseline REE. Similar results were found without adjusting for baseline REE. 


\section{DISCUSSION}

This study adds additional information to the literature regarding whether there are racial differences in the changes in REE with weight loss in women and whether body composition contributes to any racial differences in baseline REE and its changes with weight loss. Our results showed in response to a weight loss intervention, REE decreased by the same absolute magnitude in black and white women. However, after adjustment for changes in total or limb lean mass, REE was not altered by weight loss in whites. Moreover, in white women, changes in REE were related to changes in fat mass (total body, limb, or trunk); while in black women, changes in REE were not related to changes in almost all body composition measures. At baseline, REE was correlated with body weight, total and regional fat and lean mass in white women, but not in black women. Our data suggest that REE and its changes with weight loss are associated with body weight and body composition in white women, but not in black women. In addition, our results support that the REE difference between black and white women is more strongly associated with lean mass distribution, than with the total amount of lean mass.

Compared to white women of similar body weight, black women have more muscle mass and less higher metabolic rate organ mass $\left(17 ;{ }^{31}-33\right)$. Although black women were heavier in our study, our results agree with this in that after adjustment for body weight, black women had more limb lean mass but less trunk lean mass. Previous studies also show that black women have lower REE after adjustment for body size or the amount of lean and fat mass(5). This difference in REE may be partly due to their different lean mass distribution $\left(17 ;{ }^{25} ; 26\right)$; specifically, the lower trunk lean mass (which contains the high metabolic rate organs) in black women contributes to a lower REE compared to white women.

In our study, adjusting for trunk lean mass did not make a difference in the comparison of REE between the two races; however, limb lean mass seemed to play a role. We found absolute REE was not different between races, but REE of black women was lower compared to white women after adjusting for total or limb lean mass. To take into account the different body weight of black and white women in our study, we adjusted REE for limb lean mass together with body weight and REE of black women was lower. In contrast, adjusting for total lean mass together with body weight, REE was not different between the two races. These findings suggest that the amount of limb lean mass is a more important factor than total lean mass in its contribution to the REE difference in black and white women. Thus, the lower REE in black, compared to white, women may be partly due to a greater limb lean mass in black women.

Although there are numerous studies comparing REE between black and white women, there is surprisingly little information regarding racial differences in the relationships between REE and body composition. We found higher REE was associated with greater body weight, lean mass and fat mass in white women. This was not found in black women. Moreover, with weight loss, the change in REE was associated with changes in body weight and fat mass independent of baseline REE in white women. Those who lost more body weight or fat mass, had greater REE reduction. In black women, however, changes in REE were not related to changes in body weight nor fat mass. Thus, it appears that REE is more associated with body size in white than black women. There may be biological factors that are responsible for this racial difference in the associations of REE and body composition.

Our findings regarding REE changes with weight loss also support that declines in REE with weight loss are accounted for by body size (especially declines in fat mass) in white women, but not in black women. In white women, after adjustment for changes in body weight, fat mass, or lean mass, REE after the intervention was not different from baseline. In black women, however, post-intervention REE was lower than baseline after adjustment for changes in lean 
mass (total or limb or total together with trunk to limb lean mass ratio). Thus, REE decreased disproportion to the reduction in lean mass in black women. Previous studies have used pooled data from black and white participants and found REE adjusted for changes in lean and fat mass either unchanged $(16 ; 17)$ or decreased $(14 ; 34)$ after weight loss. The difference between the two races we found could be one reason why blacks lose less weight than whites with the same interventions $\left(15 ;^{21}-24\right)$. This may also put black women at a higher risk for regaining weight.

Of note, lean mass is a more metabolically active tissue and is the best predictor of REE for most individuals. However, our data in obese women show that fat mass is more strongly associated with REE. In white women, this is demonstrated by the finding that REE changes with weight loss were related to changes in total and regional fat mass, but not lean mass. In black women, this is demonstrated by the finding that, adjustment for total or regional fat mass eliminated the weight loss-induced decrease in REE, but adjustment for total or limb lean mass did not affect the reduction in REE with weight loss. The relationship in white women between REE changes and fat mass changes also tended to be independent of lean body mass changes (partial $r=0.224, p=0.075)$. Our data are not alone. One previous study also found that fat mass explained more variance in REE than lean mass in obese women (15).

Several considerations are important in drawing conclusions from our study. In accessing body composition using DXA, it is assumed that lean tissue has fixed water content. There is evidence that obesity is associated with higher hydration levels in lean tissue (35). Thus, the water content in lean mass above that is assumed by DXA will be considered as fat, resulting in an underestimation of lean mass. Because this error is likely to happen to most obese women, its influence on the relationship between REE and body composition should be small. Another issue is that all women had equal absolute energy deficit at the beginning of interventions. Therefore, they had various degree of energy deficit relative to their own energy needs. Although there was no effort to stabilize body weight prior to the post-intervention REE measurement, it is possible a few women may no longer be in negative energy balance.

In summary, the major finding of this study is that body size and composition is an important contributor to REE in white women. Although the small sample size of black women limits our ability to draw affirmative conclusions for black women, this study suggests that body size and composition in blacks may not be as important a factor for REE as in white women. With weight loss, white women decreased their REE in proportion to the amount of fat and lean mass lost, but black women decreased their REE to a greater extent than expected from their decreased body size. This could be one reason why blacks lose less weight than whites with the same interventions. In addition, our data also support that lean mass distribution is more important than total amount of lean mass in explaining the REE difference between black and white women.

\section{Acknowledgments}

This study was supported by NIH grant R01-AG/DK20583, Wake Forest University Claude D. Pepper Older Americans Independence Center (P30-AG21332), and Wake Forest University General Clinical Research Center (M01-RR07122). We are grateful to study coordinators, dietitians, and exercise physiologists of the Section on Gerontology and Geriatric Medicine and the General Clinical Research Center at Wake Forest University School of Medicine for their assistance in the conduct of this study.

\section{REFERENCES}

1. Ogden CL, Carroll MD, Curtin LR, McDowell MA, Tabak CJ, Flegal KM. Prevalence of Overweight and Obesity in the United States, 1999-2004. JAMA 2006;295:1549-1555. [PubMed: 16595758] 
2. Levine JA, Kotz CM. NEAT - non-exercise activity thermogenesis - egocentric \& geocentric environmental factors vs. biological regulation. Acta Physiologica Scandinavica 2005;184:309-318. [PubMed: 16026422]

3. Tataranni PA, Harper IT, Snitker S, et al. Body weight gain in free-living Pima Indians: effect of energy intake vs expenditure. Int J Obes Relat Metab Disord 2003;27:1578-1583. [PubMed: 12975636]

4. Astrup A, Gotzsche PC, van de WK, et al. Meta-analysis of resting metabolic rate in formerly obese subjects. Am J Clin Nutr 1999;69:1117-1522. [PubMed: 10357728]

5. Luke A, Dugas L, Kramer H. Ethnicity, energy expenditure and obesity: are the observed black/white differences meaningful? Curr Opin Endocrinol Diabetes Obes 2007;14:370-373. [PubMed: 17940465]

6. Vander Weg MW, Watson JM, Klesges RC, Eck Clemens LH, Slawson DL, McClanahan BS. Development and cross-validation of a prediction equation for estimating resting energy expenditure in healthy African-American and European-American women. Eur J Clin Nutr 2004;58:474-480. [PubMed: 14985686]

7. Nicklas BJ, Berman DM, Davis DC, Dobrovolny CL, Dennis KE. Racial differences in metabolic predictors of obesity among postmenopausal women. Obes Res 1999;7:463-468. [PubMed: 10509603]

8. Weyer C, Snitker S, Bogardus C, Ravussin E. Energy metabolism in African Americans: potential risk factors for obesity. Am J Clin Nutr 1999;70:13-20. [PubMed: 10393133]

9. Foster GD, Wadden TA, Vogt RA. Resting energy expenditure in obese African American and Caucasian women. Obes Res 1997;5:1-8. [PubMed: 9061709]

10. Forman JN, Miller WC, Szymanski LM, Fernhall B. Differences in resting metabolic rates of inactive obese African-American and Caucasian women. Int J Obes Relat Metab Disord 1998;22:215-221. [PubMed: 9539188]

11. Jakicic JM, Wing RR. Differences in resting energy expenditure in African-American vs Caucasian overweight females. Int J Obes Relat Metab Disord 1998;22:236-242. [PubMed: 9539192]

12. Carpenter WH, Fonong T, Toth MJ, et al. Total daily energy expenditure in free-living older AfricanAmericans and Caucasians. Am J Physiol 1998;274:E96-E101. [PubMed: 9458753]

13. Albu J, Shur M, Curi M, Murphy L, Heymsfield SB, Pi-Sunyer FX. Resting metabolic rate in obese, premenopausal black women. Am J Clin Nutr 1997;66:531-538. [PubMed: 9280169]

14. Leibel RL, Rosenbaum M, Hirsch J. Changes in Energy Expenditure Resulting from Altered Body Weight. N Engl J Med 1995;332:621-628. [PubMed: 7632212]

15. Foster GD, Wadden TA, Swain RM, Anderson DA, Vogt RA. Changes in resting energy expenditure after weight loss in obese African American and white women. Am J Clin Nutr 1999;69:13-17. [PubMed: 9925117]

16. Weinsier RL, Hunter GR, Zuckerman PA, et al. Energy expenditure and free-living physical activity in black and white women: comparison before and after weight loss. Am J Clin Nutr 2000;71:11381146. [PubMed: 10799376]

17. Byrne NM, Weinsier RL, Hunter GR, et al. Influence of distribution of lean body mass on resting metabolic rate after weight loss and weight regain: comparison of responses in white and black women. Am J Clin Nutr 2003;77:1368-1373. [PubMed: 12791611]

18. Doucet E, St-Pierre S, Almeras N, Despres JP, Bouchard C, Tremblay A. Evidence for the existence of adaptive thermogenesis during weight loss. Br J Nutr 2001;85:715-723. [PubMed: 11430776]

19. Brehm BJ, Spang SE, Lattin BL, Seeley RJ, Daniels SR, D'Alessio DA. The role of energy expenditure in the differential weight loss in obese women on low-fat and low-carbohydrate diets. J Clin Endocrinol Metab 2005;90:1475-1482. [PubMed: 15598683]

20. Santa-Clara H, Szymanski L, Ordille T, Fernhall B. Effects of exercise training on resting metabolic rate in postmenopausal African American and Caucasian women. Metabolism 2006;55:1358-1364. [PubMed: 16979407]

21. Kumanyika SK, Obarzanek E, Stevens VJ, Hebert PR, Whelton PK. Weight-loss experience of black and white participants in NHLBI-sponsored clinical trials. Am J Clin Nutr 1991;53:1631S-1638S. [PubMed: 2031498]

22. West DS, Elaine PT, Bursac Z, Felix HC. Weight loss of black, white, and Hispanic men and women in the diabetes prevention program. Obesity 2008;16:1413-1420. [PubMed: 18421273] 
23. Darga LL, Holden JH, Olson SM, Lucas CP. Comparison of cardiovascular risk factors in obese blacks and whites. Obes Res 1994;2:239-245. [PubMed: 16353424]

24. Wing RR, Anglin K. Effectiveness of a behavioral weight control program for blacks and whites with NIDDM. Diabetes Care 1996;19:409-413. [PubMed: 8732700]

25. Hunter GR, Weinsier RL, Darnell BE, Zuckerman PA, Goran MI. Racial differences in energy expenditure and aerobic fitness in premenopausal women. Am J Clin Nutr 2000;71:500-506. [PubMed: 10648264]

26. Gallagher D, Albu J, He Q, et al. Small organs with a high metabolic rate explain lower resting energy expenditure in African American than in white adults. Am J Clin Nutr 2006;83:1062-1067. [PubMed: 16685047]

27. Karvonen MJ, Kentala E, Mustala O. The effects of training on heart rate; a longitudinal study. Ann Med Exp Biol Fenn 1957;35:307-315. [PubMed: 13470504]

28. Cordero-MacIntyre ZR, Peters W, Libanati CR, et al. Reproducibility of DXA in obese women. J Clin Densitom 2002;5:35-44. [PubMed: 11940727]

29. Thomsen TK, Jensen VJ, Henriksen MG. In vivo measurement of human body composition by dualenergy X-ray absorptiometry (DXA). Eur J Surg 1998;164:133-137. [PubMed: 9537721]

30. Weir JB de V. New method for calculating metabolic rate with special reference to protein metabolism. J Physiol 1949;109:1-9. [PubMed: 15394301]

31. Jones A Jr, Shen W, St-Onge MP, et al. Body-composition differences between African American and white women: relation to resting energy requirements. Am J Clin Nutr 2004;79:780-786. [PubMed: 15113715]

32. Ortiz O, Russell M, Daley TL, et al. Differences in skeletal muscle and bone mineral mass between black and white females and their relevance to estimates of body composition. Am J Clin Nutr 1992;55:8-13. [PubMed: 1728823]

33. Gallagher D, Visser M, De Meersman RE, et al. Appendicular skeletal muscle mass: effects of age, gender, and ethnicity. J Appl Physiol 1997;83:229-239. [PubMed: 9216968]

34. Martin CK, Heilbronn LK, de Jonge L, et al. Effect of calorie restriction on resting metabolic rate and spontaneous physical activity. Obesity 2007;15:2964-2973. [PubMed: 18198305]

35. Haroun D, Wells JC, Williams JE, Fuller NJ, Fewtrell MS, Lawson MS. Composition of the fat-free mass in obese and nonobese children: matched case-control analyses. Int J Obes (Lond) 2005;29:29_ 36. [PubMed: 15520827] 


\section{口Black $\square$ White}

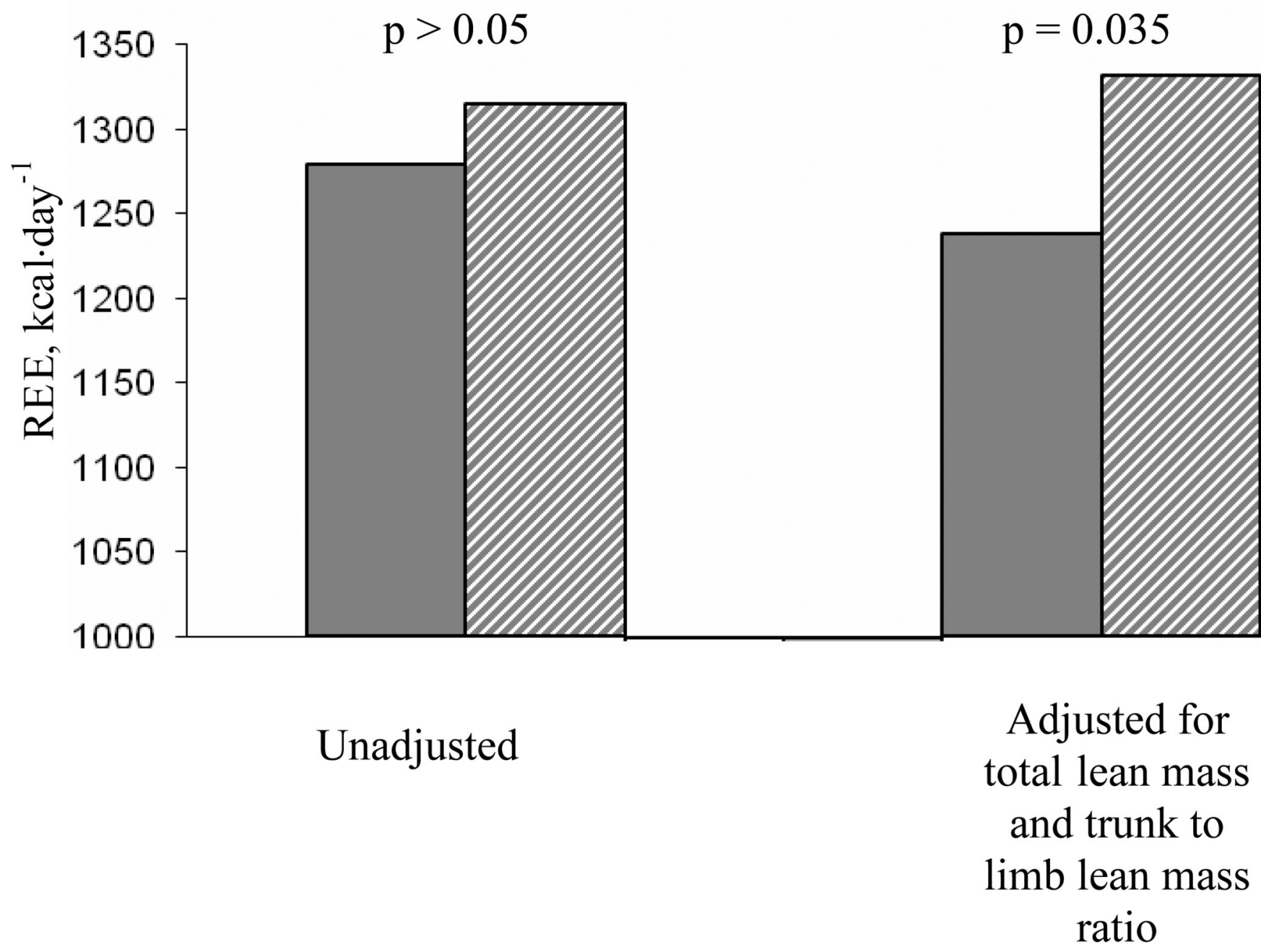

Figure 1.

Resting energy expenditure (REE) in black $(n=26)$ and white $(n=65)$ women at baseline (unadjusted and adjusted for total lean mass together with trunk to limb lean mass ratio). The unadjusted REE was similar between black and white women; REE adjusted for total lean mass together with trunk to limb lean mass ratio was lower in black, compared to white, women. 
Figure 2a.

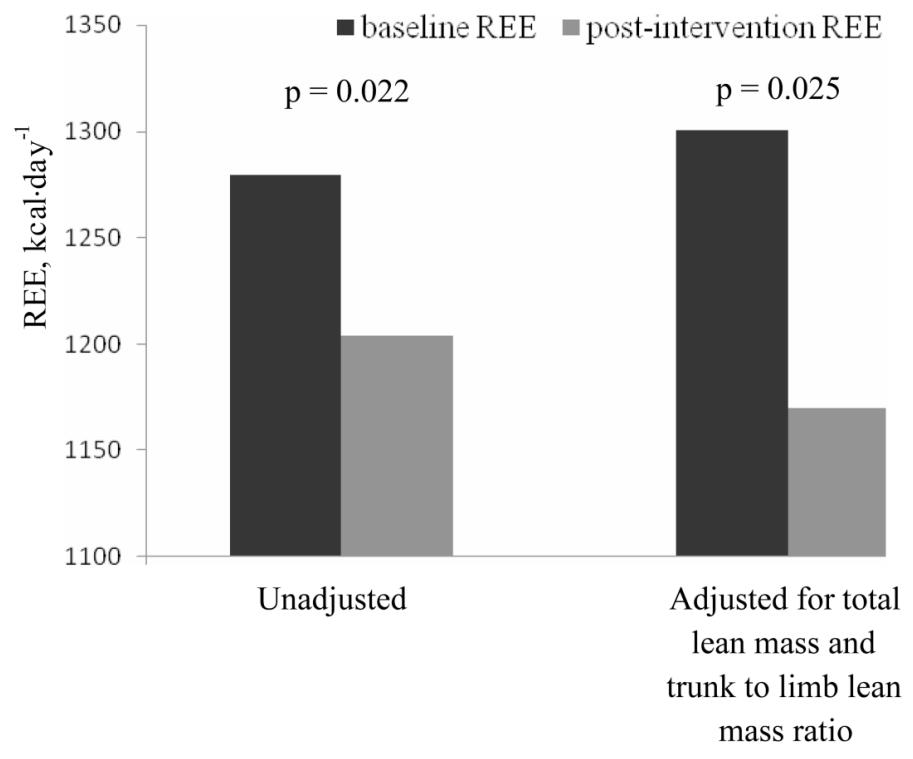

Figure 2b.

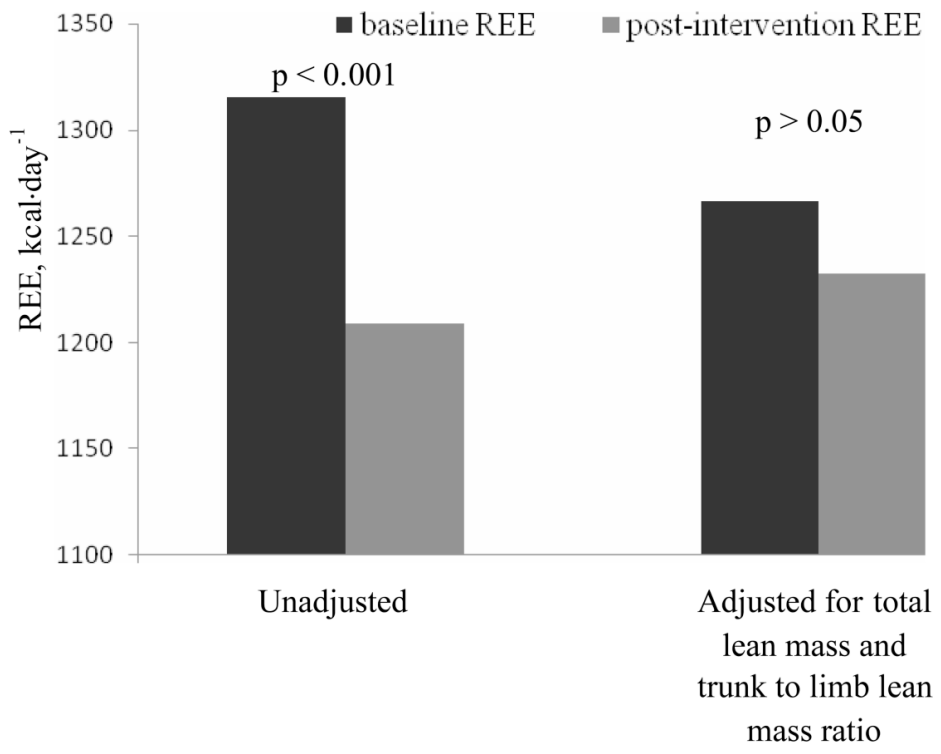

Figure 2.

Resting energy expenditure (REE) at baseline compared to after weight loss, unadjusted and adjusted for changes in total lean mass together with trunk to limb lean mass ratio, in black $(n=26$; Figure 2a) and white $(n=65$; Figure $2 b)$ women. In black women, REE (unadjusted and adjusted) decreased with weight loss. In white women, unadjusted REE decreased with weight loss; REE adjusted for total lean mass together with trunk to limb lean mass ratio was unchanged. 
Table 1

Body composition at baseline, post-intervention, and changes after intervention by race.

\begin{tabular}{|c|c|c|c|}
\hline & Black $(n=26)$ & White $(n=65)$ & ANOVA p value \\
\hline \multicolumn{4}{|l|}{ Body weight, $k g$} \\
\hline Baseline & $94.6(10.4)$ & $88.3(11.0)$ & 0.013 \\
\hline Post-intervention & $83.7(9.0)$ & $75.5(9.9)$ & $<0.001$ \\
\hline Change & $-10.9(5.3)$ & $-12.8(3.9)$ & 0.052 \\
\hline \multicolumn{4}{|c|}{ Body mass index, $\mathrm{kg} \cdot \mathrm{m}-2$} \\
\hline Baseline & $34.7(3.5)$ & $32.9(3.6)$ & 0.030 \\
\hline Post-intervention & $30.8(3.1)$ & $28.1(3.3)$ & 0.001 \\
\hline Change & $-4.0(1.9)$ & $-4.8(1.4)$ & 0.030 \\
\hline \multicolumn{4}{|c|}{ Body composition--Total body } \\
\hline \multicolumn{4}{|l|}{ Fat mass, $k g$} \\
\hline Baseline & $41.7(6.6)$ & $38.2(6.9)$ & 0.029 \\
\hline Post-intervention & $34.6(5.5)$ & $29.6(6.3)$ & 0.001 \\
\hline Change & $-7.0(4.3)$ & $-8.6(4.0)$ & 0.039 \\
\hline \multicolumn{4}{|l|}{ Lean mass, $\mathrm{kg}$} \\
\hline Baseline & $54.3(5.0)$ & $51.4(5.7)$ & 0.027 \\
\hline Post-intervention & $50.8(4.9)$ & $47.7(5.4)$ & 0.014 \\
\hline Change & $-3.4(2.3)$ & $-3.7(1.7)$ & 0.643 \\
\hline \multicolumn{4}{|l|}{$\%$ body fat } \\
\hline Baseline & $43.2(2.8)$ & $42.4(3.6)$ & 0.292 \\
\hline Post-intervention & $40.4(3.2)$ & $38.0(4.3)$ & 0.012 \\
\hline Change & $-2.9(2.6)$ & $-4.4(1.8)$ & 0.001 \\
\hline \multicolumn{4}{|c|}{ Body composition—Limb } \\
\hline \multicolumn{4}{|l|}{ Fat mass, $\mathrm{kg}$} \\
\hline Baseline & $20.6(3.3)$ & $18.4(3.8)$ & 0.013 \\
\hline Post-intervention & $17.3(2.8)$ & $14.5(3.3)$ & $<0.001$ \\
\hline Change & $-3.3(2.1)$ & $-3.9(1.3)$ & 0.101 \\
\hline \multicolumn{4}{|l|}{ Lean mass, $k g$} \\
\hline Baseline & $24.4(2.5)$ & $21.9(2.9)$ & $<0.001$ \\
\hline Post-intervention & $22.5(2.4)$ & $20.3(2.7)$ & 0.001 \\
\hline Change & $-1.9(1.3)$ & $-1.6(0.9)$ & 0.340 \\
\hline \multicolumn{4}{|c|}{ Body composition—Trunk } \\
\hline \multicolumn{4}{|l|}{ Fat mass, $\mathrm{kg}$} \\
\hline Baseline & $19.9(4.1)$ & $18.7(3.9)$ & 0.190 \\
\hline Post-intervention & $16.3(3.6)$ & $14.1(3.7)$ & 0.013 \\
\hline Change & $-3.7(2.5)$ & $-4.6(1.6)$ & 0.030 \\
\hline \multicolumn{4}{|l|}{ Lean mass, $\mathrm{kg}$} \\
\hline Baseline & $25.7(2.6)$ & $25.6(2.9)$ & 0.814 \\
\hline Post-intervention & $24.3(2.6)$ & $23.7(2.7)$ & 0.347 \\
\hline Change & $-1.5(1.3)$ & $-1.9(1.1)$ & 0.110 \\
\hline
\end{tabular}

Trunk to lean mass ratio

Obesity (Silver Spring). Author manuscript; available in PMC 2010 July 1. 


\begin{tabular}{lrrc}
\hline & Black $(\mathbf{n}=\mathbf{2 6})$ & White $(\mathbf{n}=65)$ & ANOVA p value \\
\hline Baseline & $1.06(0.07)$ & $1.17(0.09)$ & $<0.001$ \\
Post-intervention & $1.08(0.07)$ & $1.17(0.08)$ & $<0.001$ \\
Change & $0.0006(0.06)$ & $0.02(0.06)$ & 0.094 \\
\hline
\end{tabular}

Values are mean(SD). Trunk to lean mass ratio tended to increase in black women $(\mathrm{p}=0.071)$, but did not change in white women. All other post-intervention values in each race were significantly decreased from their baseline $(\mathrm{p}<0.0001)$. 